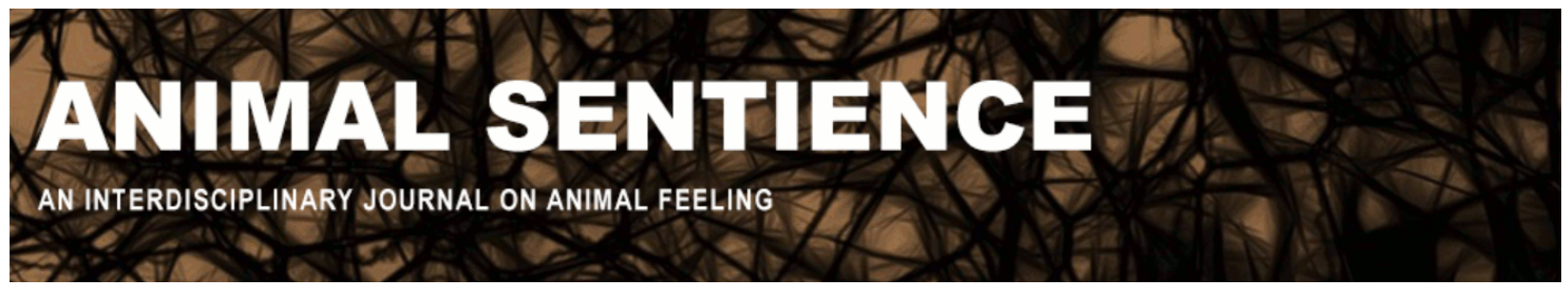

Broom, Donald M (2020) Brain complexity, sentience and welfare. Animal Sentience 29(27)

DOI: $10.51291 / 2377-7478.1613$

Date of submission: 2020-07-04

Date of acceptance: 2020-07-17

(c)

This article has appeared in the journal Animal

Sentience, a peer-reviewed journal on animal

cognition and feeling. It has been made open access,

free for all, by WellBeing International and deposited

in the WBI Studies Repository. For more information,

please contact

wbisr-info@wellbeingintl.org.

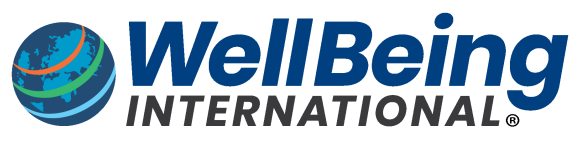

SOLUTIONS FOR PEOPLE, ANIMALS AND ENVIRONMENT 


\title{
Brain complexity, sentience and welfare
}

Commentary on Mikhalevich \& Powell on Invertebrate Minds

\author{
D. M. Broom \\ Department of Veterinary Medicine, University of Cambridge
}

\begin{abstract}
Sentience is not confined to animals with large or human-like brains. Moral standing should be accorded to all animals, not just vertebrates: invertebrates deserve moral consideration too. Carefully defining the relevant terms can help clarify the relationship between sentience and welfare. All animals have welfare but humans accord more protection to sentient animals. Humans should be less human-centred.
\end{abstract}

Donald M. Broom is Emeritus Professor of Animal Welfare at Cambridge University, Department of Veterinary Medicine and St Catharine's College. His research concerns the scientific assessment of animal welfare, cognitive abilities of animals, ethics of animal usage and sustainable farming. Website

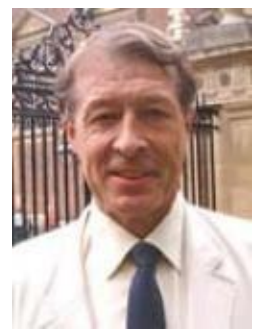

Mikhalevich \& Powell (2020) (M\&P) are biologically correct when they are scathing about the notion that there is a scala naturae and that small brains, or brains structurally different from the human brain, cannot be complex enough to allow sentience. The idea of a pyramid leading to humans is biologically naive and to say that invertebrates are "less highly evolved" is to misunderstand evolutionary mechanisms, as also pointed out by commentators Baracchi \& Bacciadonna (2020), Figdor (2020) and Marino (2020). The notion of one biology, one health and one welfare emphasises the similarities between humans and other animals. Too much focus on humans is damaging the world and humans with it (Monath et al 2010, García et al 2016, Tarazona et al 2020).

Absolute brain size is not a good indicator of cognitive ability (Broom 2003, 2014). Brain size relative to body size is influenced by the advantage of a small brain to (for example) animals that fly. As Vallortigara (2020) points out, larger brains might allow more memory storage but they do not necessarily indicate more cognitive ability. The sophisticated abilities of jumping spiders, ants, house flies, small squid, cleaner wrasse and hummingbirds are evidence for this (Reznikova 2007, Jackson and Cross 2011, Salwiczek et al 2012, Healy et al 2013, Healy and Hurley 2013, Mather and Dickel 2017). Indeed, the very sophisticated ability of cleaner wrasse to solve problems that most primates cannot solve is not obviously associated with brain complexity greater than that of related fish (Balcombe 2016, Chojnacka et al 2015).

Individuals are sentient if they have the capacity to have feelings, which includes the ability to evaluate the actions of others in relation to oneself and third parties, to remember some of one's own actions and their consequences, to assess risks and benefits and to have some degree of awareness. As explained further in Broom (2014), sentience is much more than just the sensory perception of touch sometimes implied by the verb "to feel." The range of abilities required for sentience is wide and these abilities function whether or not the 
individual is feeling something at the time. The individual animal has the biological trait of sentience and could at any particular time be using any part of that capacity. We now have evidence for all of the abilities required for sentience in a wide range of vertebrates and some molluscs and arthropods. There is a range of levels in the complexity of awareness and in the range of objects of awareness, such as environment, affect, memory or self (Sommerville and Broom 1998, Snyder et al 2004, Mendl and Paul 2008, Carruthers et al 2012, Broom 2014). Awareness is a state during which concepts of environment, of self and of self in relation to environment result from complex brain analysis of sensory stimuli or constructs based on memory. However, the reference to awareness does not imply any one level or object, or the limited sense of the term "self-awareness" involved in mirror recognition. I find it clearer to refer to awareness, rather than consciousness, because the widespread medical, veterinary and public use of conscious usually just means "not unconscious." A conscious individual is one who has the capability of perceiving and responding to sensory stimuli.

The gerund and noun "feeling" require some comment. A feeling is a brain construct, involving at least perceptual awareness. It is associated with a life regulating system, it is recognisable by the individual when it recurs and it may change behaviour or act as a reinforcer in learning (Broom 1998). Emotions are similar but they are also physiologically describable. Feelings can be considered consequences of emotions, which in turn involve awareness (Rolls 1999, Broom 2007). Positive and negative feelings -- pleasure, pain, fear, anxiety etc. -- are important adaptive mechanisms that have evolved in a range of animal groups. A pain system can be fully functional with a brain structure different from that of a mammal; such systems are described for fish, cephalopods and decapod crustacea (Mather 2013, 2020; Broom 2016; Elwood 2012, 2020) as well as for mammals and birds. Several studies of gastropod molluscs and of insects such as ants and bees indicate the possibility of a pain system with complex brain components (Broom 2013, 2014). This possibility calls for more research. As pointed out by Woodruff (2020), what are needed are functional markers of sentience (such as those discussed by Broom 2014).

Feelings are a key part of the welfare of an individual for they are components of biological coping mechanisms. However, there are many coping mechanisms, including those involved in health, which help to cope with pathology; and there is a range of other systems. Most of these involve the brain but not necessarily the most complex part of the brain (Broom and Johnson 2019). The welfare of an individual is its state as regards its attempt to cope with its environment (Broom 1986). This scientific definition can refer to any animal but not to plants or inanimate objects. Plants have many of the same mechanisms as animals (Baluška 2016) but not a nervous system. Hence we can consider the welfare of both sentient and nonsentient animals. A nematode worm can use its diverse abilities to cope with many environmental influences, so we can evaluate its welfare; but it does not fulfil the criteria for sentience. A human with a damaged brain may not be sentient but still has many coping mechanisms, so the welfare of that person can be assessed. Coping means having control of mental and bodily stability (Broom and Johnson 2019). It therefore requires a nervous system and is relevant to all animals.

Some invertebrate nervous systems do not have sufficiently complex functioning to make the organism sentient, but that does not mean that such organisms have no value. Each living individual, whether plant or animal, whether sentient or not, has value to itself and should be considered to have value to all other living individuals, including humans. This means that no living organism should be destroyed without thought; animals should be 
accorded more respect because they have a nervous system and sentient animals should be protected from actions that may harm them in a way that they feel as painful or otherwise negative. There should be some protection for all; but each of the properties of being alive, being an animal and being sentient confers a different moral status. The concept of "us" or "we" expressed by humans today increasingly includes all sentient beings, not just Homo sapiens.

M\&P argue that people should accord invertebrates moral consideration. All individuals of any animal species can have moral actions addressed to them. They could accordingly be said to have interests and hence it is logical that people should accord moral standing to them. In light of the widespread evidence for moral actions, moral codes and their evolution (de Waal 1996, Broom 2003, 2006) in many non-human species, each individual who persistently shows moral behaviour might be called a "moral agent." It can be argued that invertebrate animals take many complex decisions and hence have free will (Brembs 2011). Social insects exhibit considerable altruistic behaviour (Reznikova 2007). Further studies of moral behaviour are needed, however, to assess whether some invertebrates might also be considered moral agents.

\section{References}

Balcombe, Jonathan (2016) In praise of fishes: Précis of What a fish knows (Balcombe 2016). Animal Sentience 8(1).

Baluška, František (2016) Should fish feel pain? A plant perspective. Animal Sentience 3(16).

Baracchi, David and Baciadonna, Luigi (2020) Insect sentience and the rise of a new inclusive ethics. Animal Sentience 29(18).

Brembs, B. (2011). Towards a scientific concept of free will as a biological trait: spontaneous actions and decision-making in invertebrates. Proceedings of the Royal Society $B$ : Biological Sciences, 278(1707), 930-939.

Broom, D.M. (1986). Indicators of poor welfare. British Veterinary Journal, 142, 524-526.

Broom, D.M. (1998). Welfare, stress and the evolution of feelings. Advances in the Study of Behavior, 27, 371-403.

Broom, D.M. (2003). The Evolution of Morality and Religion (pp. 259). Cambridge: Cambridge University Press.

Broom, D.M. (2006). The evolution of morality. Applied Animal Behaviour Science, 100, 20-28.

Broom, D.M. (2007). Cognitive ability and sentience: which aquatic animals should be protected? Diseases in Aquatic Organisms, 75: 99-108.Broom, D.M. (2013). The welfare of invertebrate animals such as insects, spiders, snails and worms. In Animal suffering: from science tolaw, international symposium, ed. Kemp, T. A. van der \& Lachance, M., 135-152. Paris: Éditions Yvon Blais.

Broom, D.M. (2014). Sentience and animal welfare (pp. 200). Wallingford: CABI.

Broom, D.M. (2016). Fish brains and behaviour indicate capacity for feeling pain. Animal Sentience 5(1).

Broom, D.M. \& Johnson, K.G. (2019). Stress and animal welfare: key issues in the biology of humans and other animals, $2^{\text {nd }}$ edn. (pp 230). Cham, Switzerland: Springer Nature.

Carruthers, P., Fletcher, L. \& Ritchie, J.B., (2012). The evolution of self-knowledge. Philosophical Topics, 40, 13-37. 
Chojnacka, D., Isler, K., Barski, J.J. \& Bshary, R., (2015). Relative brain and brain part sizes provide only limited evidence that machiavellian behaviour in cleaner wrasse is cognitively demanding. PLoS One, 10(8), p.e0135373.

Elwood, R.W. (2012). Evidence for pain in decapod crustaceans. Animal Welfare 21(S2):23-7.

Elwood, R. W. (2020) Do arthropods respond to noxious stimuli purely by reflex? Animal Sentience, 29(10).

Figdor, Carrie (2020) Relationship between cognition and moral status needs overhaul. Animal Sentience 29(3).

García, R., Appleby, M.C., Manteca, X., Scott- Park, F., Smith, C. \& Velarde, A. (2016). One welfare-A platform for improving human and animal welfare. Veterinary Record, 179, 412-413,.

Healy, K., McNally, L., Ruxton, G.D., Cooper, N. \& Jackson, A.L. 2013. Metabolic rate and body size are linked with perception of temporal information. Animal Behaviour, 86, 685-696.

Healy, S. D., \& Hurly, T. A. (2013). What hummingbirds can tell us about cognition in the wild. Comparative Cognition \& Behavior Reviews, 8, 13-28.

Jackson, R.R. \& Cross, F.R. (2011). Spider cognition. Advances in Insect Physiology, 41, 115-174.

Marino, Lori (2020) Sentience in all organisms with centralized nervous systems. Animal Sentience 29(19).

Mather, Jennifer (2019) What is in an octopus's mind? Animal Sentience 26(1)

Mather, J.A. (2013). Do cephalopods have pain and suffering. In Animal suffering: from science to law, international symposium, ed. Kemp, T. A. van der and Lachance, M. Paris: Éditions Yvon Blais.

Mather, J.A. \& Dickel, L., (2017). Cephalopod complex cognition. Current Opinion in Behavioral Sciences, 16, 131-137.

Mendl, M. \& Paul, E.S. (2008). Do animals live in the present? Current evidence and implications for welfare. Applied Animal Behaviour Science, 113, 357-382.

Mickhalevich, I. \& Powell, R. (2020). Minds without spines: evolutionary inclusive animal ethics. Animal Sentience, 2020.329, 25 pages.

Monath,T.P., Kahn, L.H., \& Kaplan,B. (2010). One health perspective. ILAR Journal, 51,193-198.

Reznikova, Z.A. (2007). Animal intelligence: from individual to social cognition. Cambridge: Cambridge University Press.

Rolls, E.T. (1999). The brain and emotion. Oxford: Oxford University Press.

Salwiczek, L.H., Prétôt, L., Demarta, L., Proctor, D., Essler, J., Pinto, A.I., Wismer, S., Stoinski, T., Brosnan, S.F. \& Bshary, R. (2012). Adult cleaner wrasse out-perform capuchin monkeys, chimpanzees and orang-utans in a complex foraging task derived from cleaner-client reef fish cooperation. PLoS One, 7(11), p.e49068.

Snyder, A., Bossomaier, T. \& Mitchell, D.J. (2004). Concept formation: object attributes dynamically inhibited from conscious awareness. Journal of Integrative Neuroscience, 3 , 31-46.

Sommerville, B.A. \& Broom, D.M. (1998). Olfactory awareness. Applied Animal Behaviour Science, 57, 269-286.

Tarazona, A.M., Ceballos, M.C. \& Broom, D.M. (2020). Human relationships with domestic and other animals: one health, one welfare, one biology. Animals, 10, 43; (pp. 23)

Vallortigara, G. (2020) Lessons from miniature brains: Cognition cheap, memory expensive (sentience linked to active movement?). Animal Sentience 29(17).

Waal, F. de (1996). Good natured. Cambridge MA: Harvard University Press.

Woodruff, M. L. (2020) Whether invertebrates are sentient matters to bioethics and science policy. Animal Sentience 29(16). 